\title{
Fracture Mechanical Behavior of Cracked Cantilever Roof with Large Cutting Height Mining
}

\author{
Zenghui Zhao $\mathbb{D}^{1,2}$ Wei Sun, ${ }^{1,2}$ Mingzhong Zhang, ${ }^{1,2}$ Xiaojie Gao, ${ }^{1,2}$ and Shaojie Chen \\ ${ }^{1}$ State Key Laboratory of Mining Disaster Prevention and Control Co-founded by Shandong Province \\ and the Ministry of Science and Technology, Qingdao 266590, China \\ ${ }^{2}$ College of Energy and Mining Engineering, Shandong University of Science and Technology, Qingdao 266590, China
}

Correspondence should be addressed to Zenghui Zhao; tgzyzzh@163.com

Received 15 September 2019; Accepted 3 February 2020; Published 13 April 2020

Academic Editor: Roberto Palma

Copyright $(92020$ Zenghui Zhao et al. This is an open access article distributed under the Creative Commons Attribution License, which permits unrestricted use, distribution, and reproduction in any medium, provided the original work is properly cited.

\begin{abstract}
Accurately predicting the roof collapse span is crucial in ensuring the safe production of thick seam mining with large mining height, which is easy in forming a "cantilever beam" structure. Considering roof damage caused by roadway excavation and coal seam mining disturbance, the fracture mechanics model of large mining height roof cantilever beam with nonpenetrating cracks was established. The roof was divided into two parts: the crack-affected area and the crack-unaffected area. The analytical expression of the boundary between the two areas was established by fracture mechanics methods. Based on the boundary equation, the influences of crack size, crack inclination, roof lithology, and roof thickness on the roof crack-affected area were analyzed in detail. Finally, the accuracy of the theoretical model was verified by numerical experiments using the extended finite element method. The results demonstrate that the size of the area affected by the vertical crack increases with the increase of the crack size and the thickness of the roof. The influence of the crack decreases with the increase of roof lithology. The probability of early periodic collapse of a thin roof with the crack is increased. When the crack is completely located in the interior of the roof, the crack-affected area shrinks greatly with the decrease of the crack inclination. When the crack inclination is small, the crack will not cause the early collapse of the roof. Overall, the conclusions obtained are of great significance for predicting the collapse span of a cantilever roof with initial damage in large mining height.
\end{abstract}

\section{Introduction}

The total of thick seam, the main mining seam in China, reserves and production accounts for about $45 \%[1,2]$. Comprehensive mechanized mining of thick coal seams mainly contains slice mining, top coal caving mining, and large cutting height mining [3]. Large cutting height mining has been widely used for its high output rate and good economic benefits. However, there are still many technical problems in large cutting height mining. For example, with the increase of mining height and the height of overburden caving zone, the low-level key strata that can form articulated balance structure can not form stable "voussoir beam" structure because of large rotation, but form "cantilever" structure to collapse directly [4]. So, the accurate prediction of the roof periodic collapse span is salient for ensuring the safe mining of coal seams. In fact, thanks to complex geological conditions such as diagenesis, high temperature, and high humidity, as well as the influence of excavation roadway and mining, it is inevitable that there will be nonpenetrating cracks in the roof [5-9], The roof is made into a discontinuous structure, which will collapse earlier than continuous structure, resulting in serious safety accidents and economic losses. Thus, it is of profound significance to clarify the influence of the nonpenetrating cracks on the roof periodic collapse span with large mining height, whether for the support design of working face or for the safe and efficient production of coal mine.

Nowadays, the construction of roof collapse model mostly follows the assumption of uniformity and continuity. On the basis of these assumptions, scholars put forward the classical hypothesis of mine pressure, such as pressure arch hypothesis, precrack hypothesis, and articulated rock block hypothesis $[10,11]$. The most influential underground 
pressure theories in China are the voussoir beam theory [12], the key stratum theory [13], and the transmission rock beam theory [14]. In recent years, considerable research efforts have been devoted to underground pressure theories for different mining environments and methods. Aiming at the problem of shallow thin bedrock seam mining, Huang and $\mathrm{Li}$ established a cantilever beam model based on Winkler elastic foundation theory. The results show that bedrock will break ahead of the coal wall during the period of periodic pressure [15]. Some scholars combine Protodyakonov's theory with the voussoir beam theory and then put forward the balanced composite structure of "arch" on "beam." The research indicates that the width of "arch" is equal to the basic roof periodic weighting span [16, 17]. Relevant studies demonstrate that the mining of deeply inclined coal seams is different from that of horizontal coal seams, and its periodic collapse span is affected by the position of working face, the way of underhand mining and overhand mining, and the crack inclination of the coal seam. The periodic weighting span at the top and bottom of the working face is slightly larger than that in the upper middle, middle, and lower middle of it. The roof periodic collapse span is shorter in overhand mining than in underhand mining. The periodic weighting span decreases with the increase of the crack inclination of the coal seam [18-20]. In addition, some scholars have considered the damage effect of roof stratum and regarded the roof as a cantilever beam with cracks. Equations of the roof periodic collapse span and support working resistance are obtained. The effects of crack inclination, roof length, and thickness on the roof periodic collapse span and support working resistance were analyzed $[21,22]$. Yang et al. [23] further established the mechanical model of a cracked plate by using thin plate theory and analyzed the roof caving motion state of longwall face large cutting height mining. Unfortunately, these discussions are all aimed at the specific location of the cracks, not involving the different positions of cracks. And there is not any indepth study of the boundaries of the crack-affected area and the crack-unaffected area. In fact, the position of crack determines its stress state. Under a certain load, the different positions of cracks have different effects on the roof periodic collapse span.

Much work of the roof periodic collapse span so far has been based on the assumption of uniform continuous media. Although some studies have established the roof model with cracks, the range of cracks affecting roof collapse motion remains an unanswered question. The innovations of this study are as follows:

(1) Introduce the crack into the analysis of the periodic collapse of the roof with large cutting height mining and establish a cantilever beam model with the nonpenetrating crack.

(2) Release the constraint condition of crack position. The studying content is not limited to the crack at specific location.

(3) Determine the scope of the cracks that cause the roof to collapse periodically in advance.
Therefore, aiming at the problem of the roof periodic collapse span with the nonpenetrating crack with large cutting height mining, this study proposed to establish a cantilever beam model with the nonpenetrating crack, determined the location of crack, which can cause the early periodic collapse of a roof, and revealed the influence of crack size, crack inclination, roof lithology, and roof thickness on the crack-affected area. Necessary supporting theories for roof support design were provided.

\section{Analysis Model of the Roof with the Nonpenetrating Crack in Large Cutting Height}

The schematic diagram of the roof with the nonpenetrating crack in large cutting height is given, as the principle displayed in Figure 1. Under the condition of fully mechanized mining with large cutting height or extra-large cutting height, the working face advances from right to left. Due to the obvious increase in mining height and caving zone height, the fractured rock produced by the immediate roof collapse can not fill the goaf. Because of the large amount of rotary subsidence, the main roof and low-level key strata can not contact the caved rock in the goaf after breaking to form a stable masonry beam structure. Low-level key strata may enter the caving zone and break in the form of a cantilever beam, which forms periodic weighting [4]. The $l$ in the figure represents the roof periodic collapse span. Under the action of long-term geological structure and mining disturbance, random cracks at different lengths and directions will occur in rocks. In order to facilitate the analysis, these cracks are regarded as a main crack. It is assumed that the effect of the principal crack on roof fracture represents the effect of all cracks on it. When the crack satisfies the fracture condition under the external force, the crack begins to crack, which causes the roof to collapse ahead of time. Under the same external load, this effect is closely related to the location of the crack. The zone where the crack that causes the roof to collapse ahead of time is located is called the crack-affected area, and the other zones are called the crack-unaffected area.

\section{Analysis of the Boundary of the Crack- Affected Area in Large Cutting Height}

3.1. Analysis of the Crack-Free Roof Periodic Collapse Span. Figure 2 is a simplified diagram of the crack-free. Only the bending deformation of the roof under dead weight is considered. The thickness of the roof is $h$ and the length is $L$. Under the action of distributed load $q, q=h \gamma$, and $\gamma$ is the specific weight of the roof.

The bending moment equation of the roof is

$$
M(x)=\frac{q}{2}(L-x)^{2}=\frac{h \gamma}{2}(L-x)^{2} .
$$

The expression of normal stress at the point $A$ is 


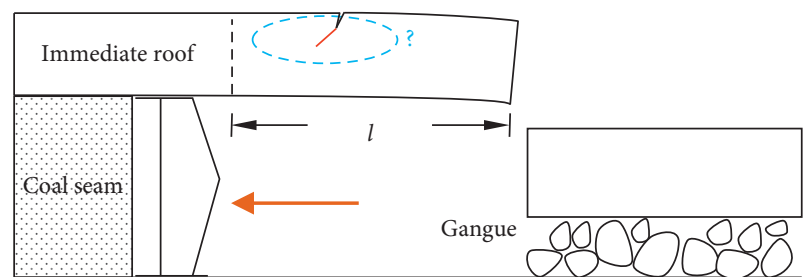

FIgURE 1: Roof periodic collapse in large mining height workface.

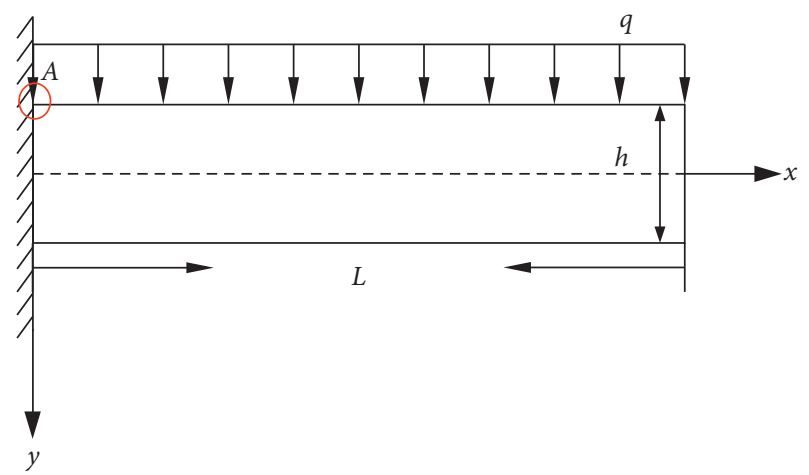

FIGURE 2: Stress analysis diagram of crack-free roof.

$$
\sigma_{A}=\frac{M y}{I_{z}}=\frac{3 \gamma L^{2}}{h} .
$$

The working face is propelled from right to left. When the maximum bending tensile stress (point $A$ ) reached the tensile strength, that is, $\sigma_{A}=\left[\sigma_{t}\right]$, the root of cantilever beam is cracked. The roof periodic collapse span is calculated:

$$
L=\sqrt{\frac{\left[\sigma_{t}\right] h}{3 \gamma}}
$$

As can be seen from equation (3), $L$ is affected by the physical properties and thickness of the rock.

\subsection{Analysis of the Location of the Internal Crack That Caused} the Roof Periodic Collapse in Advance. Cracks on the compression side of beams do not expand and have little effect on the bending deformation of beams. The tensile strength of rock is far lower than the compressive strength [24]. Therefore, we focus on the boundary of the crack-affected area when the crack is located on the tension side of the beam.

Without loss of generality, a roof model with random cracks is established as shown in Figure 3. The crack length is $2 a$, and the coordinate of the crack center is $\left(x_{0}, y_{0}\right)$. As shown in Figure 4, unit body with the internal crack is taken.

It can be seen that the kind of this crack is a combination of open mode (mode I) and slide mode (mode II), i.e., I-II composite mode crack. In Figure 4, $\beta$ is included angle of the inclined direction of crack and horizontal direction, $\theta$ is an initiation angle, and $\sigma$ is the tensile stress at the midpoint of the crack, which is approximately used to represent the

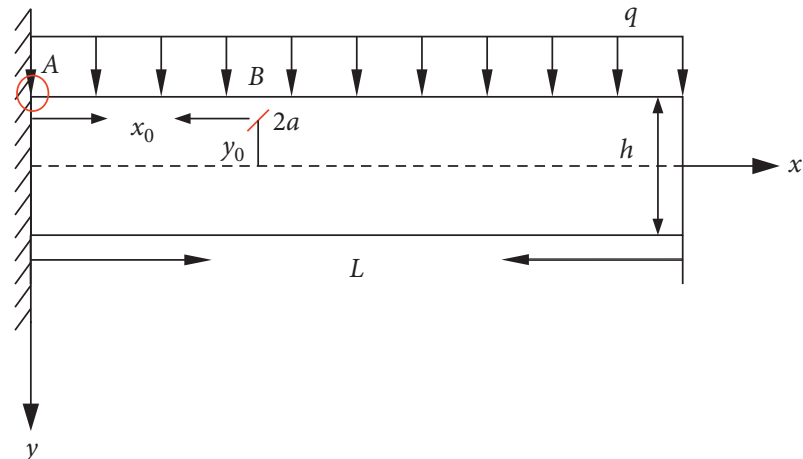

FIgURE 3: Stress analysis diagram of roof with internal crack.

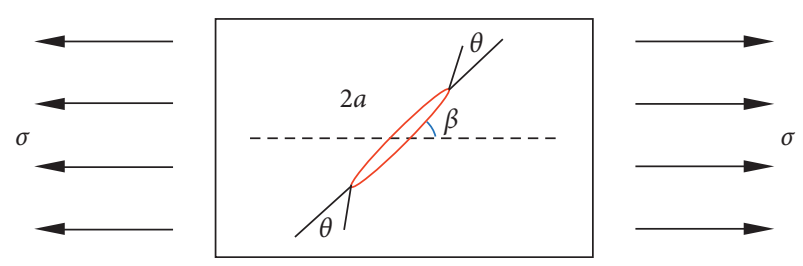

FIgURE 4: Stress analysis diagram of internal crack.

tensile stress on the unit body. The stress $\sigma$ is decomposed into normal stress and shear stress along the crack surface. The corresponding stress intensity factors are, respectively $[25,26]$ :

$$
\begin{aligned}
K_{\mathrm{I}} & =\sigma \sqrt{\pi a} \sin ^{2} \beta, \\
K_{\mathrm{II}} & =\sigma \sqrt{\pi a} \sin \beta \cos \beta .
\end{aligned}
$$

Stress field near the crack tip is

$$
\begin{aligned}
& \sigma_{r}=\frac{\cos (\theta / 2)}{2 \sqrt{2 \pi r}} K_{\mathrm{I}}(3-\cos \theta)+\frac{\sin (\theta / 2)}{2 \sqrt{2 \pi r}} K_{\mathrm{II}}(3 \cos \theta-1), \\
& \sigma_{\theta}=\frac{\cos (\theta / 2)}{2 \sqrt{2 \pi r}}\left[K_{\mathrm{I}}(1+\cos \theta)-3 K_{\mathrm{II}} \sin \theta\right], \\
& \tau_{\theta}=\frac{\cos (\theta / 2)}{2 \sqrt{2 \pi r}}\left[K_{\mathrm{I}} \sin \theta-K_{\mathrm{II}}(3 \cos \theta-1)\right] .
\end{aligned}
$$

According to the maximum circumferential stress theory, when the circumferential stress along the direction of initiation angle $\theta$ reaches the critical value $\sigma_{\theta C}$, the crack will expand in an unstable way:

$$
\sigma_{\theta}\left(K_{\mathrm{I}}, K_{\mathrm{II}}, \theta\right)=\sigma_{\theta \mathrm{C}} .
$$

The critical instability condition of the crack is obtained by equations (8) and (9):

$$
\cos \frac{\theta}{2}\left(K_{\mathrm{I}} \cos ^{2} \frac{\theta}{2}-\frac{3}{2} K_{\mathrm{II}} \sin \theta\right)=K_{\mathrm{IC}} .
$$

Initiation angle $\theta$ is 


$$
\cos \theta=\frac{\cos ^{2} \beta+\sqrt{\sin ^{2} \beta+8 \cos ^{2} \beta}}{1+8 \cos ^{2} \beta} .
$$

Combining equations (7) and (8), the critical stress $\sigma_{B c}$ can be obtained:

$$
\sigma_{B c} \sqrt{\pi a} \cos \frac{\theta}{2} \sin \beta\left(\sin \beta \cos ^{2} \frac{\theta}{2}-\frac{3}{2} \cos \beta \sin \theta\right)=K_{\mathrm{IC}}
$$

The normal stress at the point B is obtained by equation (1):

$$
\sigma_{B}=\frac{M y}{I_{z}}=\frac{6 \gamma y_{0}\left(L-x_{0}\right)^{2}}{h^{2}} .
$$

The boundary equation of the crack-affected area by equations (9) and (10) is as follows:

$$
y_{0}\left(\sqrt{\frac{\left[\sigma_{t}\right] h}{3 \gamma}}-x_{0}\right)^{2}=\frac{K_{\mathrm{IC}}}{\left(6 \gamma / h^{2}\right) \sqrt{\pi a} \cos (\theta / 2) \sin \beta\left(\sin \beta \cos ^{2}(\theta / 2)-(3 / 2) \cos \beta \sin \theta\right)}
$$

3.3. Analysis of the Location of the Edge or Neutral Layer Crack That Caused the Roof Periodic Collapse in Advance. When a crack appears at the upper boundary or the neutral layer, it becomes an edge crack problem, which is different from an internal crack problem. Since there is no exact analytical expression for the stress intensity factor of the crack not perpendicular to the boundary, only the problem of the crack perpendicular to the boundary is studied here.

Figures 5(a) and 5(b) are roof models with cracks at the edge and at the neutral layer, respectively. Taking the edge crack as an example, unit body with the edge crack is taken, as shown in Figure 6:

This crack belongs to a pure mode I crack, and its stress intensity factor is [27]

$$
K_{\mathrm{I}}=1.12 \sigma \sqrt{\pi 2 a} \approx 1.58 \sigma \sqrt{\pi a} .
$$

The normal stress at the point $B$ is obtained from equation (1):

$$
\sigma_{B}=\frac{M y}{I_{z}}=\frac{6 \gamma y_{0}\left(L-x_{0}\right)^{2}}{h^{2}}
$$

where $y_{0}$ takes $a$ or $(h /(2-a))$ and $\sigma$ is equal to the normal stress at the midpoint of the crack.

The boundary equation of the crack-affected area by equations (12) and (13) is as follows:

$$
y_{0}\left(\sqrt{\frac{\left[\sigma_{t}\right] h}{3 \gamma}}-x_{0}\right)^{2}=\frac{K_{\mathrm{IC}}}{\left(9.48 \gamma / h^{2}\right) \sqrt{\pi a}} .
$$

3.4. Analysis of the Location of the Vertical Crack That Caused the Roof Periodic Collapse in Advance. According to the analysis of Sections 3.2 and 3.3, when included angle of the inclined direction of crack and horizontal direction is $90^{\circ}$, the boundary equation of the crack-affected area is

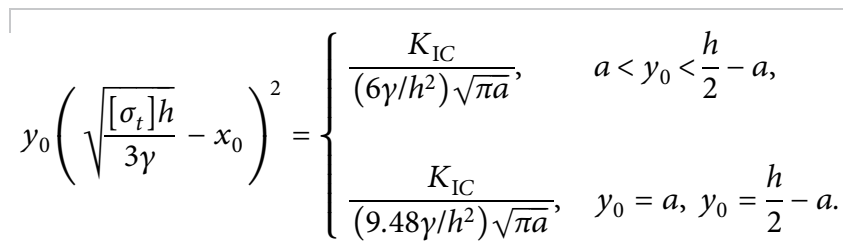

In this chapter, the relationship between stress and strain is not involved in the process of analysis and derivation. Therefore, the derivation results are applicable to plane stress and plane strain problems.

\section{Analysis and Discussion}

4.1. Parameter. It can be seen from equation (9) that the boundary equation is affected by crack size, crack inclination, roof thickness, and roof lithology. A pertinent study of these factors is to reveal the laws of their impact. The parameters of the roof are shown in Table 1.

4.2. Influence of Vertical Crack Size and Roof Lithology on the Crack-Affected Area. The crack length is $0.2 \mathrm{~m}, 0.3 \mathrm{~m}$, $0.4 \mathrm{~m}, 0.5 \mathrm{~m}$, and $0.6 \mathrm{~m}$, respectively. The roof thickness is $6 \mathrm{~m}$. The roofs are taken from the four types of strata listed in Table 1. Figure 7 shows the variation rules of different roof lithologies and crack sizes on the roof crack-affected area. Figures 7 (a) -7 (d) correspond to the roofs from the hard roof to the soft roof. On the premise of only considering the dead weight of the roof, the crack-free roof periodic collapse span decreases with the softening of the roof, from $26.35 \mathrm{~m}$ to $20.52 \mathrm{~m}$. The upper-left zone of tension side of the roof is defined as the crack-affected area, while the lower right zone is defined as the crack-unaffected area. For the same lithologic roof, the boundary lines of the crack-affected area are roughly of the same shape under different crack sizes: the upper and lower parts of the line are straight, while the middle part is the curve convex outward to the lower right. With the increase in crack size, the crack-affected area increases continuously, but the growth rate slows down. As 


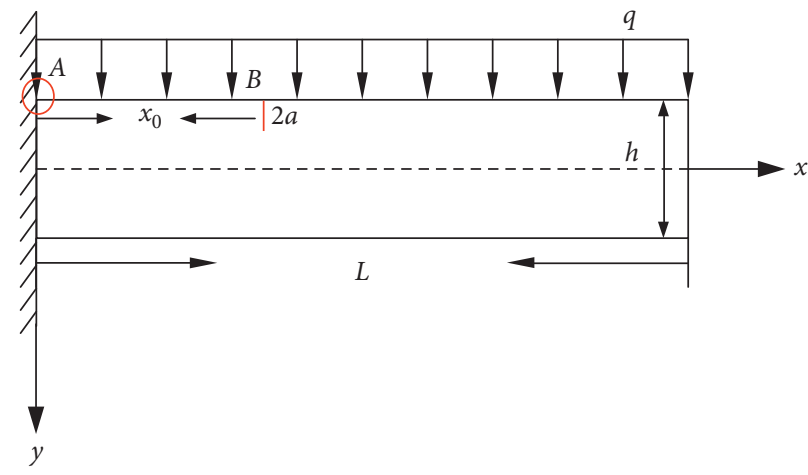

(a)

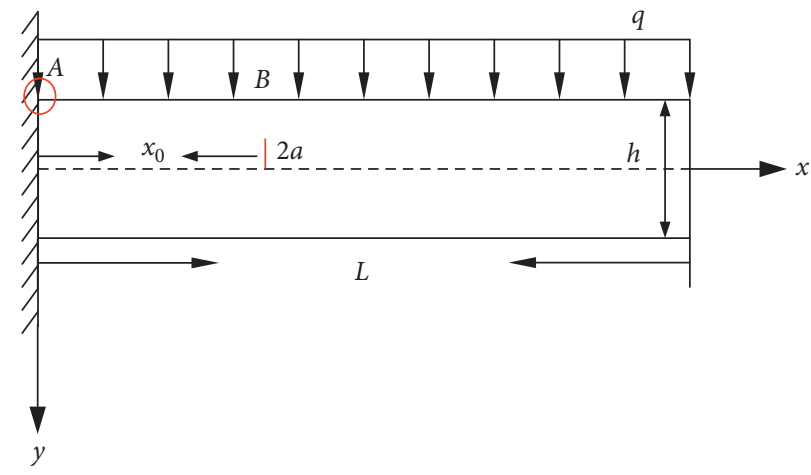

(b)

FIgURE 5: Stress analysis diagrams of roof with crack. (a) Roof with crack at edge. (b) Roof with crack at neutral layer.

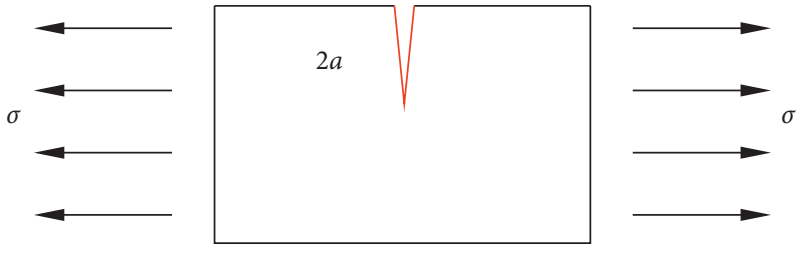

FIgURE 6: Stress analysis diagram of edge crack.

TABLE 1: Parameters of roofs.

\begin{tabular}{lcccc}
\hline & $\gamma\left(\mathrm{N} / \mathrm{m}^{3}\right)$ & $\sigma_{c}\left(\times 10^{6} \mathrm{~Pa}\right)$ & $K_{\mathrm{IC}}\left(\times 10^{6} \mathrm{~N} \cdot \mathrm{m}^{-3 / 2}\right)$ & $h(\mathrm{~m})$ \\
\hline Gabbro & 28224 & 9.8 & 3.62 & \\
Granite & 25872 & 7 & 2.33 & $2,3,4,5,6$ \\
Marble & 26460 & 6.5 & 1.99 & \\
Oil shale & 15680 & 3.3 & 0.37 & \\
\hline
\end{tabular}

shown in Figure 7(d), for the softer roof with the large crack, the crack-affected area will expand to the neutral layer, and its proportion of the total crack-affected area will gradually increase.

Figure 8 shows the change rules of the boundary of the crack-affected area with the same roof thickness and crack size in various lithologies. The crack length is $0.2 \mathrm{~m}$ and the roof thickness is $6 \mathrm{~m}$. For the same crack size and roof thickness, the crack-affected area gradually expands with the softening of the roof. The upper and lower parts of the crackaffected areas of gabbro roof, granite roof, and marble roof are roughly of the same shape. The area of their middle part increases slightly in turn, while the size of the crack-affected area by the oil shale roof increases significantly. The soft crack-free roof has a short periodic collapse span, and the crack-affected area of the soft roof with a crack is large. Therefore, the soft roof is more likely to early periodic collapse due to the crack, which entails a more considerable risk.

4.3. Influence of Roof Thickness on the Roof Crack-Affected Area with Vertical Crack. Take the marble roof as an example. The crack length is $0.2 \mathrm{~m}$ and the roof thickness is 2-6 $\mathrm{m}$. Figure 9 shows the influence law of roof thickness on the boundary of the crack-affected area of the marble roof with a vertical crack. As the roof thickness increases, the periodic collapse span of the roof without a crack increases. Change trends of the boundaries of the crack-affected area remain the same.

Figure 10 shows charts of the crack-affected area and its proportion to total roof area. As the roof thickness increases, the size of the crack-affected area gradually increases, but its proportion to the total area gradually decreases, which is between $3 \%$ and $5.5 \%$. It demonstrated that, for the same roof with the same crack, the smaller the thickness of the roof is, the higher the probability that the roof collapses in advance due to the crack.

4.4. Influence of the Internal Crack Inclination on the Roof Crack-Affected Area. Figure 11 shows the effect of various internal crack inclinations on the crack-affected areas. The crack length is $0.2 \mathrm{~m}$, the roof thickness is $6 \mathrm{~m}$, and $\beta=75^{\circ}$, $80^{\circ}, 85^{\circ}, 90^{\circ}$, respectively. It can be viewed from the figure that the size of crack-affected area shrinks significantly with the decrease of the crack inclination. When the crack inclination is lower than a certain value, the size of the crackaffected area is 0 . This indicates that when the crack appears at any position inside the roof with this inclination, the roof will not collapse in advance due to the crack. As shown in Figure 12, the initiation angle decreases with the increase of the crack inclination.

\section{Numerical Simulation}

In order to further verify the conclusions of theoretical analysis, the fracture mechanics model of the roof with a crack is established by XFEM method.

5.1. Basic Principles of Extended Finite Element Method. For the numerical solution of cracks, the traditional finite element method has strict requirements: (1) geometric segmentation of the model is required at the crack location; (2) high density mesh is required near the crack tip; (3) it is necessary to have a rough prediction of the crack propagation path, and to simulate crack propagation by 

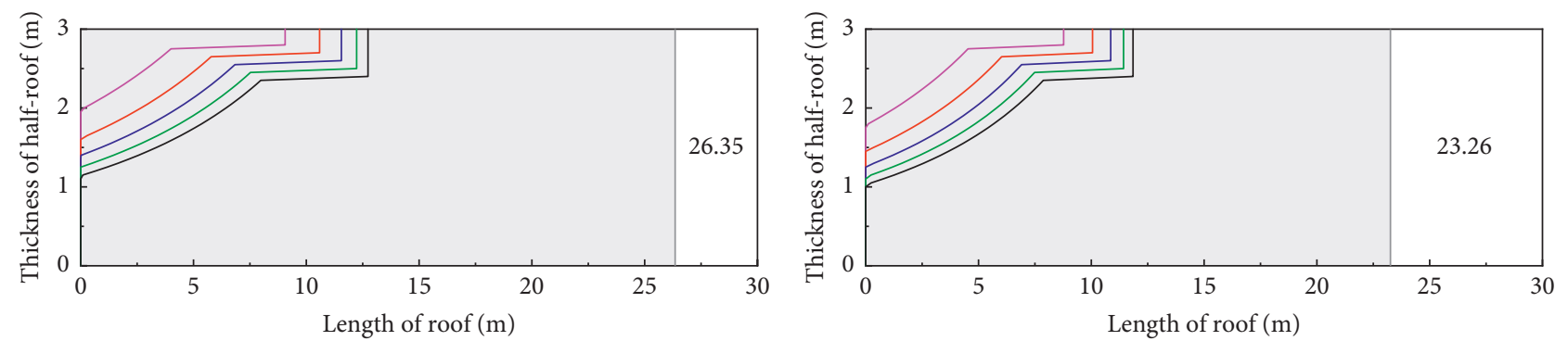

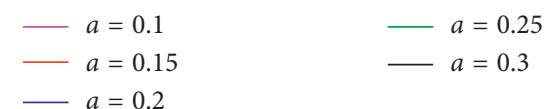

(a)

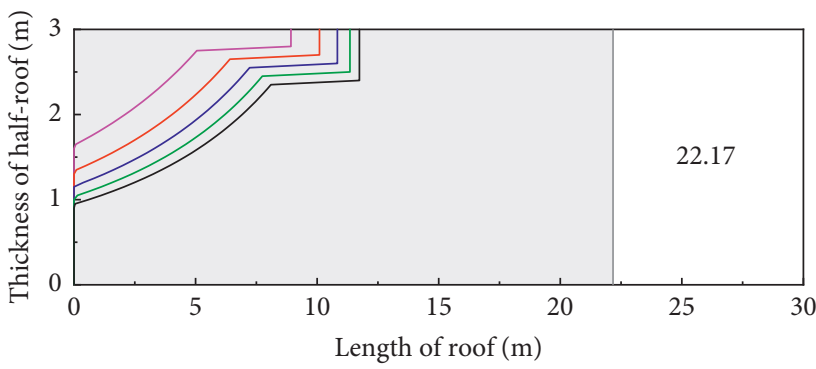

$-a=0.25$

$-a=0.3$

(c)

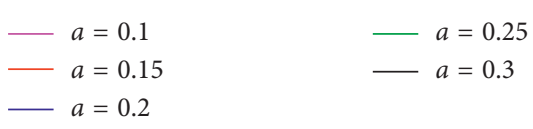

(b)

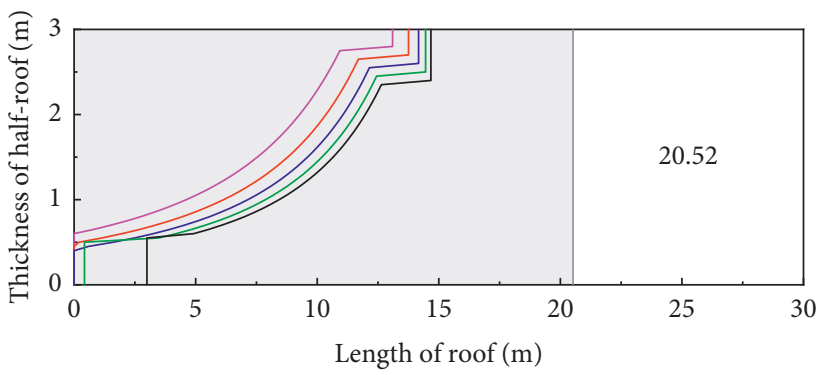

(d)

FIGURE 7: Effect of different crack sizes on the boundary of crack-affected area. (a) Gabbro. (b) Granite. (c) Marble. (d) Oil shale.

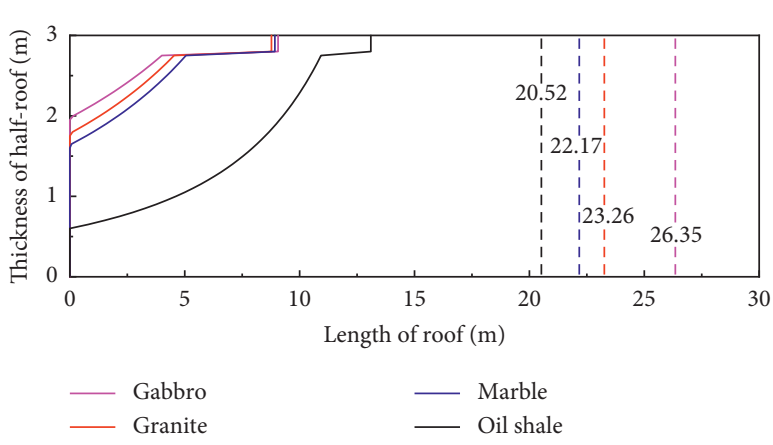

FIGURE 8: Effect of different roof lithology on the boundary of crack-affected area.

continuous mesh reconstruction. The extended finite element method is a very effective method in solving discontinuous problems like cracks. Cracks can occur inside the mesh. The cracks are independent of the mesh, and the initiation and development of the cracks are entirely from the results of the model calculations. The essence of the extended finite element method is to describe the discontinuous displacement field by introducing discontinuous displacement mode, using finite element shape function as partitions of unity [28-30].

The extended finite element method is similar to the conventional finite element method. The displacement function is substituted for the virtual work equation to

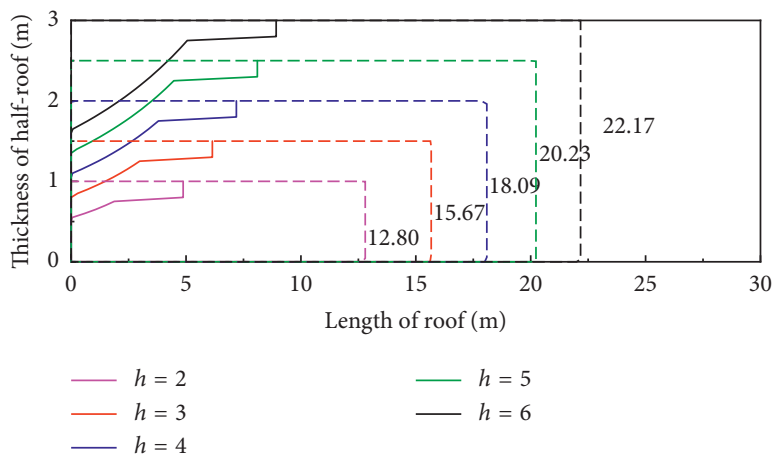

FIGURE 9: Effect of different roof thicknesses on the boundary of crack-affected area.

derive the basic governing equation of the finite element method. The biggest difference and the most critical point is the construction of displacement function. The approximate displacement interpolation function of the extended finite element method is [31-33]

$$
\begin{aligned}
U= & \sum_{i \in N_{1}} N_{i}(x) u_{i}+\sum_{j \in N_{2}} N_{j}(x) H(x) a_{j} \\
& +\sum_{k \in N_{3}} N_{k}(x) \sum_{\alpha=1}^{4} F_{\alpha}(x) b_{k}^{\alpha} .
\end{aligned}
$$




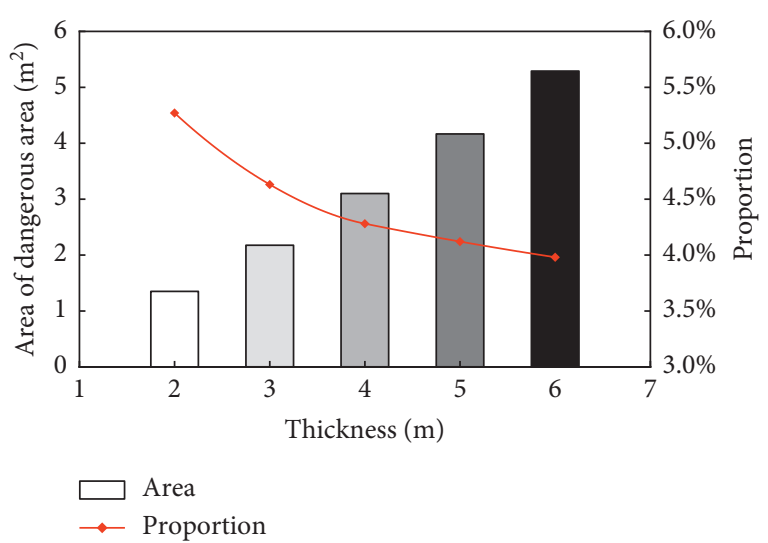

FIGURE 10: Size of crack-affected area vs. proportion of crack-affected area.

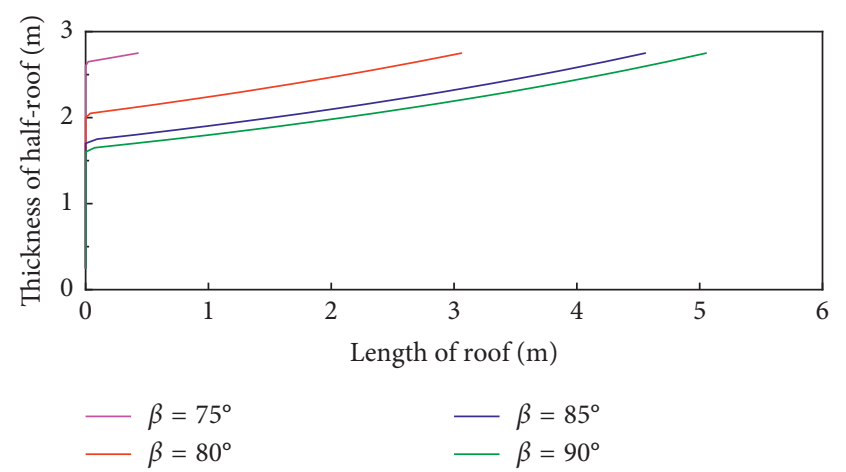

FIGURE 11: Effect of different crack inclinations on the boundary of crack-affected area.

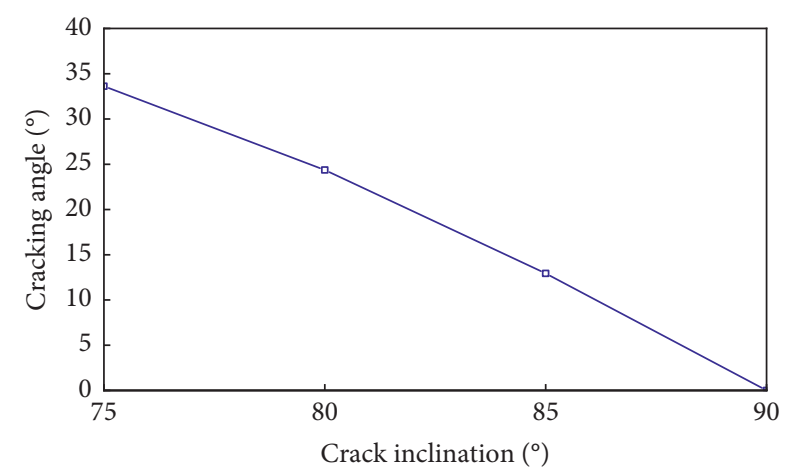

FIGURE 12: Relation between crack inclination and initiation angle.

As shown in Figure 13, the function divides all the nodes near the crack into three categories. The function classifies all nodes near the crack into three categories. The first item describes the node displacement of the standard elements without the crack (set: $N_{1}$ ); the second item describes the node displacement of the elements penetrated by the crack (set: $N_{2}$ ); the third term describes the node displacement of the elements including the crack tip (set: $\left.N_{3}\right) . a_{j}$ and $b_{k}^{\alpha}$ are extra degrees of freedom at nodes. And $H(x)$ is the enrichment function of the elements penetrated by the crack,

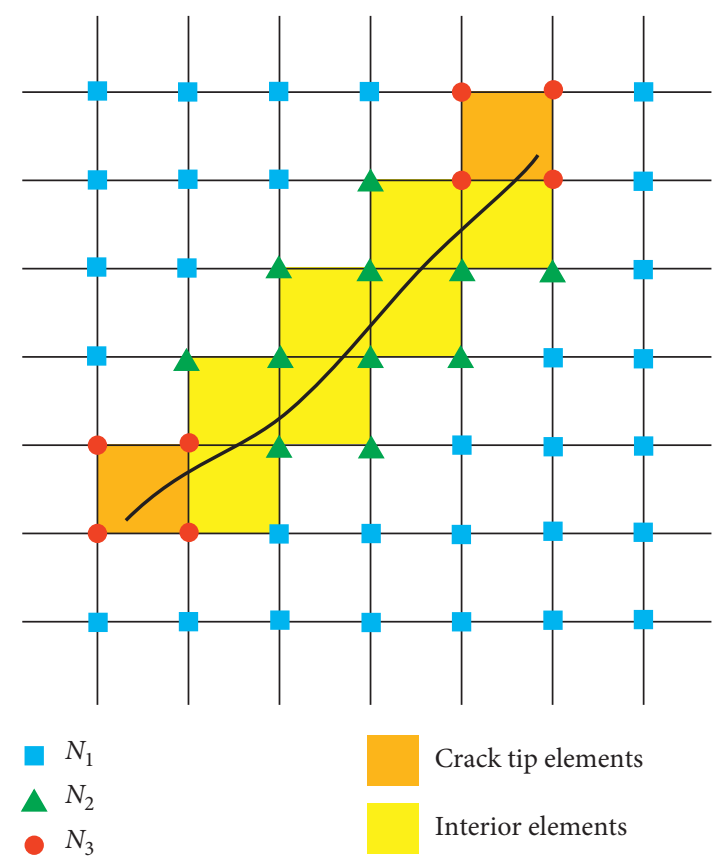

Figure 13: Node and element near crack.

and it is the jump function. $F_{\alpha}(x)$ is the enrichment function of the crack tip elements:

$$
\begin{aligned}
{\left[F_{\alpha}(r, \theta), \alpha\right.} & =1 \sim 4] \\
& =\left\{\sqrt{r} \sin \frac{\theta}{2}, \sqrt{r} \cos \frac{\theta}{2}, \sqrt{r} \sin \frac{\theta}{2} \sin \theta, \sqrt{r} \cos \frac{\theta}{2} \sin \theta\right\},
\end{aligned}
$$

where $(r, \theta)$ is the polar coordinate system of the crack tip.

\subsection{Numerical Simulation of the Roof with the Nonpenetrating}

Crack. The results of theoretical analysis were numerically verified by ABAQUS. Taking the marble roof as an example, the two-dimensional plane stress model was used for analysis without considering the width of the roof. The roof was set to an elastoplastic constitutive model. Elastic modulus is $55.8 \mathrm{GPa}$, Poisson's ratio is 0.25 , tensile strength is $6.5 \mathrm{MPa}$, density is $2700 \mathrm{~kg} / \mathrm{m}^{3}$, length is $22.17 \mathrm{~m}$, and thickness is $6 \mathrm{~m}$. The crack length is $0.2 \mathrm{~m}$. The left side of the roof is completely fixed, the upper part is affected by the distributed load, and the load collection degree $(q)$ is $15.8760 \mathrm{kN} / \mathrm{m}$. The element type is CPS4R, and the number of elements is 380 .

Figure 14 shows the simulation results of cracks at different locations. Figures 14(a)-14(d) correspond to crackfree, the crack located at the edge of crack-affected area, the crack located inside crack-affected area, and the crack located at the edge of the crack-unaffected area, respectively. The dotted line is the boundary line between the crack-affected area and the crack-free area, and the circle indicates a picture magnified 100 times in the vicinity of the crack. The roof in Figure 14(a) has no cracks, and the maximum tensile stress exists in the upper-left corner of the roof. The cracks in Figures 14(b) and 14(c) both expand, which can cause the roof to collapse in advance. The edge crack in Figure 14(b) 
S, S11 (Avg: 75\%)

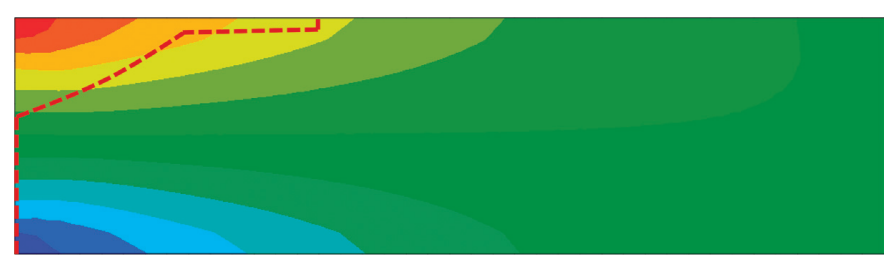
$+6.503 e+06$ $+4.658 e+06$ $+2.814 e+06$ $+9.696 e+05$ $-8.748 e+05$

$-2.719 e+06$

$-4.564 e+06$

(a)

S, S11 (Avg: 75\%)

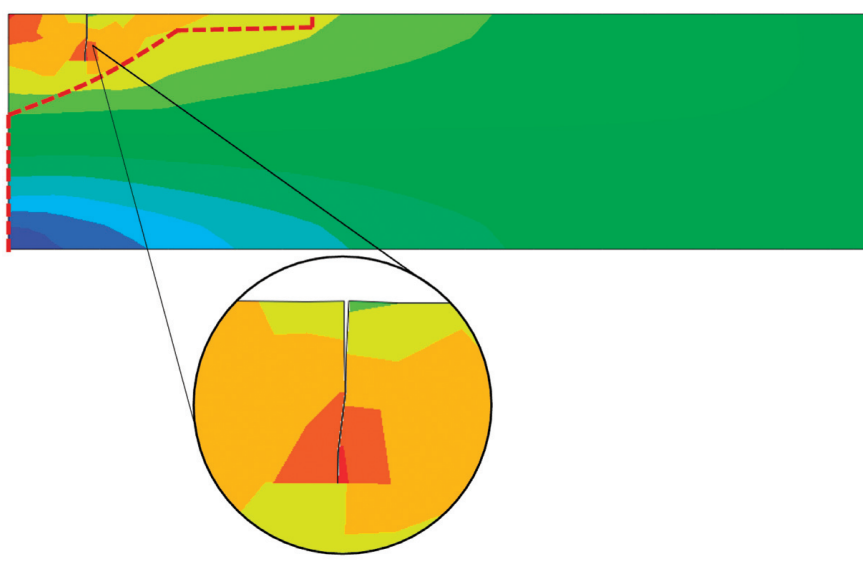

$+6.647 e+06$

$+4.759 e+06$

$+2.871 e+06$

$+9.835 e+05$

$-9.045 e+05$

$-2.793 e+06$

$-4.681 e+06$

$-6.569 e+06$

(b)

S, S11 (Avg: 75\%)

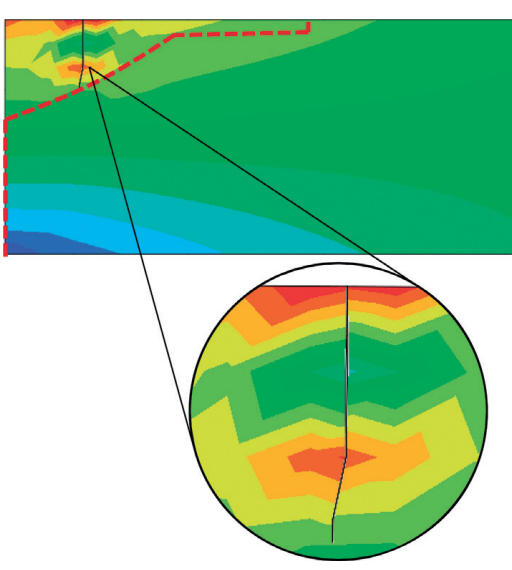

$+6.172 e+06$

$++4.533 e+06$

$+2.895 e+06$

$+1.256 e+06$

$-3.827 e+05$

$-2.021 e+06$

$-3.660 e+06$

$-5.298 e+06$

(c)

S, S11 (Avg: 75\%)

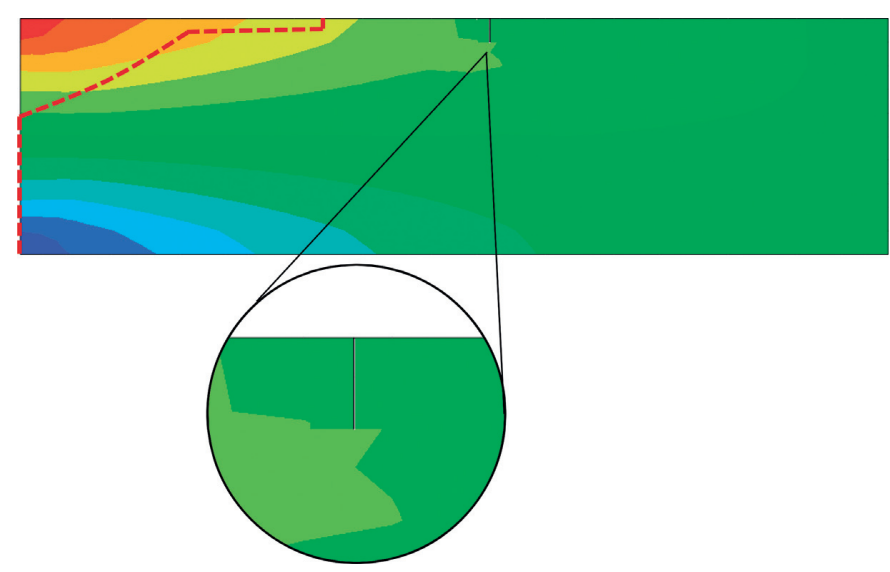

$+6.383 e+06$

$+4.571 e+06$

$+2.760 e+06$

$+9.489 e+05$

$-8.623 e+05$

$-2.673 e+06$

$-4.485 e+06$

$-6.296 e+06$

(d)

FiguRE 14: Normal stress of roof under different crack positions. (a) Crack-free. (b) At the edge of crack-affected area. (c) In the interior of crack-affected area. (d) In the crack-unaffected area. 
extends to the inside. There are large tensile stresses near the lower crack tip and the upper-left corner of the roof. The internal crack in Figure 14(c) expands inward and outward. Restricted by XFEM itself, when the crack reaches the edge of the roof, the propagation stops. Large tensile stresses exist at the tips on both sides of the crack. In Figure 14(d), the crack is in the crack-unaffected area, the crack does not expand, there is no stress concentration at the crack tip, and there is a maximum tensile stress at the upper-left corner of the roof. Theoretical analysis suggests that cracks in the crack-affected area will expand, causing the roof to collapse in advance. The cracks located in the crack-unaffected area will not expand, and the stress distribution of the roof is basically similar to the roof with no crack. In summary, the numerical simulation results are consistent with the theoretical analysis results.

\section{Conclusion}

In view of the periodic collapse of the roof with the nonpenetrating crack with large cutting height, a fracture mechanics model of the cantilever beam with the nonpenetrating crack was established. The quantitative functional relationship between crack size, crack inclination, roof thickness, roof lithology, and the boundary of the crackaffected area was deduced. The influence of the crack location on roof failure was revealed, and further numerical simulations were carried out to verify the analysis results. Relevant conclusions are as follows:

(1) For vertical cracks, the influence range of cracks on the roof periodic collapse expands with the increase of the crack size, but its growth rate slows down. This effect decreases with the increase of the roof lithology. In the soft roof with a large size crack, the possibility of the crack-affected area near the neutral layer is greater.

(2) For vertical cracks, the crack-affected area increases with the increase of the roof thickness, but the proportion of the crack-affected area to the total roof area decreases. For thin roof, the probability of early roof periodic collapse caused by the crack is higher.

(3) For the internal crack, the crack-affected area decreases greatly with the decrease of the crack inclination. The initiation angle decreases with the increase of the crack inclination. The initiation angle of the vertical crack is 0 , and the crack is cracked in the vertical direction. When the crack inclination is less than a certain angle, the roof is all the crackaffected area. And the roof always cracks at its end, which is consistent with the crack-free roof.

(4) The numerical simulation shows that the crack in the crack-affected area can expand, and there is a large tensile stress at the crack tip, which will lead to the roof collapse in advance. The crack in the crackunaffected area can not expand. The stress distribution of the roof is similar to that of the crack-free roof, and the roof will not collapse in advance.

\section{Data Availability}

The calculation data used to support the findings of this study are included within the article.

\section{Conflicts of Interest}

The authors have no conflicts of interest.

\section{Acknowledgments}

This work was supported by the National Natural Science Foundation of China (51774196 and 51774194), National Natural Science Foundation of China and Shandong Province joint Program (U1806209), SDUST Research Fund (Grant/Award Number: 2019TDJH101), and China Postdoctoral Science Foundation (No. 2016M592221).

\section{References}

[1] J. C. Wang and S. H. Zhong, "The present status and the key issues to be resolved of thick seam mining technique in China," Sciencepaper Online, vol. 3, no. 11, pp. 829-834, 2008.

[2] Z. Zhao, W. Sun, S. Chen, W. Wang, and Q. Wang, "Coupling model of jointed rock mass and rock bolt in offshore LPG underground storage," Energy Science \& Engineering, pp. 116, 2019.

[3] J. H. Wang, "Key technology for fully-mechanized top coal caving with large mining height in extra-thick coal seam," Journal of China Coal Society, vol. 38, no. 12, pp. 2089-2098, 2013.

[4] J. L. Xu and J. F. Ju, "Structural morphology of key stratum and its influence on strata behaviors in fully-mechanized face with super-large mining height," Chinese Journal of Rock Mechanics and Engineering, vol. 30, no. 8, pp. 1547-1556, 2011, in Chinese.

[5] M. S. Diederichs, P. K. Kaiser, and E. Eberhardt, "Damage initiation and propagation in hard rock during tunnelling and the influence of near-face stress rotation," International Journal of Rock Mechanics and Mining Sciences, vol. 41, no. 5, pp. 785-812, 2004.

[6] T. Xu, T.-h. Yang, C.-f. Chen, H.-1. Liu, and Q.-1. Yu, "Mining induced strata movement and roof behavior in underground coal mine," Geomechanics and Geophysics for Geo-Energy and Geo-Resources, vol. 1, no. 3-4, pp. 79-89, 2015.

[7] X. Z. Lyu, Z. H. Zhao, X. J. Wang, and W. M. Wang, "Study on the permeability of weakly cemented sandstones," Geofluids, vol. 2019, Article ID 8310128, 14 pages, 2019.

[8] Z. Zhao, Q. Ma, Y. Tan, and X. Gao, "Load transfer mechanism and reinforcement effect of segmentally yieldable anchorage in weakly consolidated soft rock," Simulation, vol. 95, no. 1, pp. 83-96, 2019.

[9] Z. H. Zhao, Y. L. Tan, S. J. Chen, Q. Ma, and X. J. Gao, "Theoretical analyses of stress field in surrounding rocks of weakly consolidated tunnel in a high-humidity deep environment," International Journal of Rock Mechanics and Mining Sciences, vol. 122, Article ID 104064, 2019.

[10] H. Shi and F. X. Jiang, "Sturctural theories of overlying strata in longwall faces and their new development," Journal of Shandong University of Science and Technology (Natural Science), vol. 24, no. 1, pp. 21-25, 2005, in Chinese. 
[11] S. M. Ma, W. Y. Lyu, and B. Y. Sun, "Current situation and trend of research on ground pressure theory in deep stope," Coal Engineering, vol. 10, pp. 87-89, 2010.

[12] M. G. Qian and T. C. Liu, Mining Pressure and Strata Control, China Coal Industry Publishing House, Beijing, China, 1984.

[13] M. G. Qian, X. X. Miao, J. L. Xu, and X. B. Mao, Key Strata Theory in Ground Control, China University of Mining and Technology Press, Beijing, China, 2003.

[14] Z. Q. Song, Practical Mine Pressure Control, China University of Mining and Technology Press, Beijing, China, 1988.

[15] Q. X. Huang and S. G. Li, "Breakage of coal seam roof in shallow and thin basement rock and its control," Ground Pressure and Strata Control, no. Z1, pp. 22-25, 1995, in Chinese.

[16] H. F. Huang, Tectonic motion and control of overburden in thin bedrock fully-mechanized sublevel caving face, Ph.D. thesis, China University of Mining and Technology, Beijing, China, 2012.

[17] F. Du, H. B. Bai, H. F. Huang, and G. H. Jiang, "Mechanical analysis of periodic weighting of main roof in longwall top coal caving face with thin-bedrock roof," Journal of China University of Mining \& Technology, vol. 42, no. 3, pp. 362-369, 2013.

[18] Y. F. Zhao, X. Y. Zhang, and M. Tu, "Roof caving characteristic and srata behavior in exploiting steep coal seams," Journal of Mining \& Safety Engineering, vol. 24, no. 2, pp. 231-234, 2007.

[19] Y. D. Zhang, J. Y. Cheng, X. X. Wang, Z. J. Feng, and M. Ji, "Thin plate model analysis on roof break of up-dip or downdip mining stope," Journal of Mining \& Safety Engineering, vol. 27, no. 4, pp. 487-493, 2010, in Chinese.

[20] Z. Y. Ti, H. Y. Qin, and Y. M. Chen, "Influence of coal seam dip angle on periodic weighting feature in fully-mechanized sublevel caving mining," Journal of China University of Mining \& Technology, vol. 44, no. 5, pp. 817-822, 2015, in Chinese.

[21] Z. H. Chen, J. J. Feng, C. C. Xiao, and R. H. Li, "Fracture mechanical model of key roof for fully-mechanized top-coal caving in shallow thick coal seam," Journal of China Coal Society, vol. 32, no. 5, pp. 449-452, 2007.

[22] D. F. Yang, L. F. Zhang, M. Chai, B. Li, and Y. F. Bai, "Study of roof breaking law of fully mechanized top coal caving mining in ultra-thick coal seam based on fracture mechanics," Rock and Soil Mechanics, vol. 37, no. 7, pp. 2033-2039, 2016.

[23] D. F. Yang, Z. H. Chen, J. W. Sun, L. N. Wang, and Q. Gao, "Cracked plate mechanical model for large mining height and langwall face of roof caving," Journal of Southeast University (Natural Science Edition), vol. 46, no. S1, pp. 210-216, 2016.

[24] Z. Zhao, M. Zhang, Q. Ma, and B. Chen, "Deviation effect of coaxiality on the rock Brazilian split," Advances in Mathematical Physics, vol. 2020, Article ID 5782457, 8 pages, 2020.

[25] J. Cheng and S. S. Zhao, Fracture Mechanics, Science Press, Beijing, China, 2006.

[26] J. F. Knott, Fundamentals of Fracture Mechanics, Gruppo Italiano Frattura, Cassino, Italy, 1973.

[27] S. Al Laham and S. I. Branch, Stress Intensity Factor and Limit Load Handbook, British Energy Generation Limited, London, UK, 1998.

[28] X. J. Fang and F. Jin, "Extended finite element method based on abaqus," Engineering Mechanics, vol. 24, no. 7, pp. 6-10, 2007, in Chinese.

[29] Z. L. Ru, C. R. Zhu, Y. L. Zhang, and H. B. Zhao, "Study of fracture problem with extended finite element method," Rock and Soil Mechanics, vol. 32, no. 7, pp. 2171-2176, 2011.
[30] L. L. Guo, Z. F. Chen, J. Y. Luo, and G. Chen, "A review of the extended finite element method and its applications," Chinese Quarterly of Mechanics, vol. 32, no. 4, pp. 612-625, 2011.

[31] T. Belytschko and T. Black, "Elastic crack growth in finite elements with minimal remeshing," International Journal for Numerical Methods in Engineering, vol. 45, no. 5, pp. 601-620, 1999.

[32] N. Moës, J. Dolbow, and T. Belytschko, "A finite element method for crack growth without remeshing," International Journal for Numerical Methods in Engineering, vol. 46, no. 1, pp. 131-150, 1999.

[33] J. Dolbow, N. Moës, and T. Belytschko, "Discontinuous enrichment in finite elements with a partition of unity method," Finite Elements in Analysis and Design, vol. 36, no. 3-4, pp. 235-260, 2000. 